\title{
Thoracoplasty in tuberculosis
}

\author{
Kanak Palmar, Gilbert Berdine MD
}

$\boldsymbol{B}_{\text {efore the development of effective therapy for }}$ tuberculosis (TB), folk remedies encouraged patients to engage in physical activity and get enough sunlight, and sanatoriums offered isolation of TB patients, good nutrition, and adequate bed rest. ${ }^{1}$ No scientific proof exists for the effect these approaches had on disease. John Alexander, one of the presidents of the American Association for the Thoracic Surgeon, advocated compression therapy which could be achieved by creating an artificial pneumothorax or by thoracoplasty to repair the diseased lung. ${ }^{2,3}$ It was postulated that lung collapse would limit the spread of the disease by inducing fibrosis and encapsulating the infected area. By collapsing the treated lung, ventilation to the treated lung was impaired, thereby reducing oxygen levels in the lung tissue and inhibiting the growth of the oxygen-dependent tuberculous bacillus.

Thoracoplasty is a procedure that targets the resolution of a cavity (pleural or pulmonary) by collapsing the chest wall through rib resection. It was a major advance in pulmonary tuberculosis surgery and resulted in sputum negativity in $75 \%$ of survivors. ${ }^{4}$

Friedrich first developed a radical extrapleural thoracoplasty involving resection of 2-9 ribs but sparing the periosteum, intercostal musculature, and nerves. This procedure was unlike the radical intrapleural thoracoplasty developed by Schede in the 1890s that resected the entire chest wall en bloc overlying the empyema cavity. Sauerbruch developed paravertebral thoracoplasty that preferentially resected the posterior portion of the ribs and transverse processes of the thoracic vertebrae. Briefly in thoracoplasty, the ribs overlying the empyema cavity are resected, the cavity is curetted, the bronchial

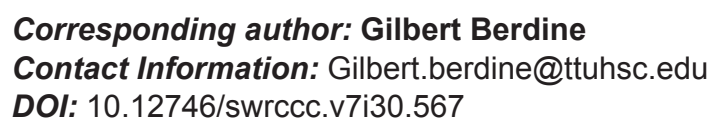

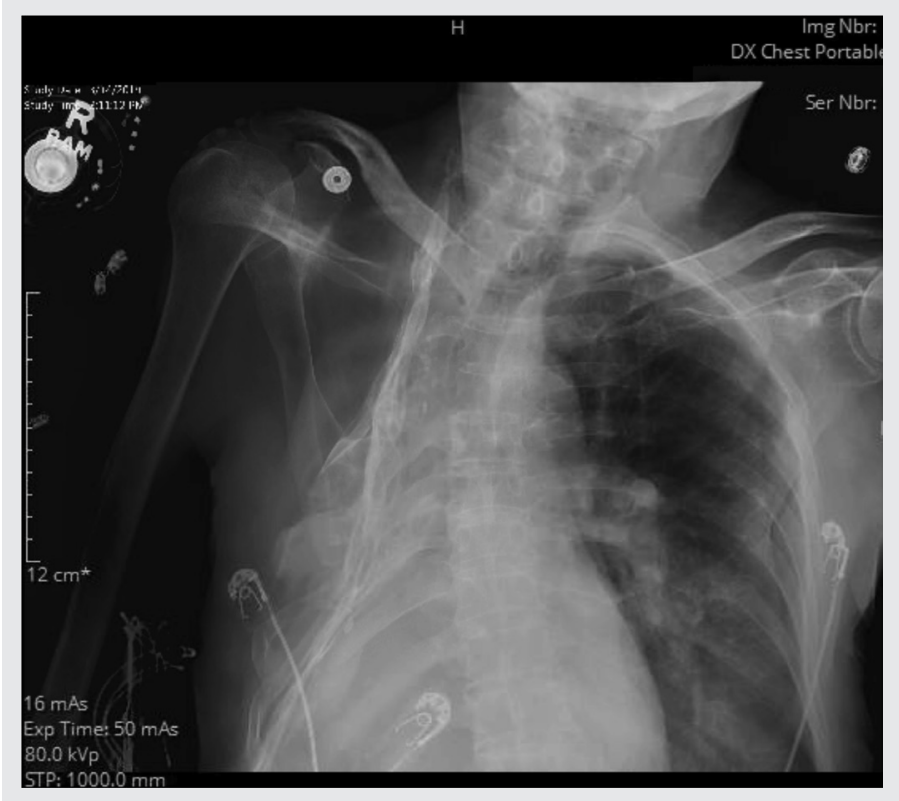

Figure. Plain frontal view chest radiograph that illustrates the results from a thoracoplasty.

fistula, if present, is closed, and the parietal plane is sutured to the mediastinal plane.

Currently, two variants of thoracoplasty are used: modified thoracoplasty and minimally invasive video assisted extrapleural thoracoplasty. ${ }^{5}$ Video assisted extrapleural thoracoplasty spares the muscle belly and has a smaller deformation of the thoracic cage. In combination with thoracoplasty, extrapleural apical dissection (apicolysis) was suggested to remove the apical cavity of TB.

The discovery of anti-tuberculosis drugs-starting with streptomycin in 1944 and rifampin in 1946dramatically changed TB therapy. Thoracoplasty is considered a mutilating operation, leading to undesirable anatomic, functional, and cosmetic sequelae. However, despite its bad reputation, there are a few remaining situations, such as pleural empyema not amenable to decortication, parenchymal disease with limited lung re-expansion, and refractory 
empyema status post therapeutic pneumonectomy, in which thoracoplasty should be considered. The indications of thoracoplasty for the treatment of pulmonary infections include severe fibrotic changes of residual lung and multidrug resistant infections. Persistent bronchopulmonary fistulae are frequently solved with the use of muscle flaps in combination with thoracoplasty.

Positive outcomes for patients with multidrug resistant tuberculosis and increasing number of resistant cases confirms the relevance of this approach. ${ }^{6-9}$ Thoracoplasty is usually considered in desperate cases with failed medical treatments and failure of standard procedures of resection or decortications.

Keywords: tuberculosis, thoracoplasty, chest wall

Article citation: Palmar K, Berdine G. Thoracoplasty in tuberculosis. The Southwest Respiratory and Critical Care Chronicles 2019;7(30):71-72

From: Department of Internal Medicine, Texas Tech University Health Sciences Center, Lubbock, Texas

Submitted: 5/2/2019

Accepted: 5/5/2019

Reviewer: Kenneth Nugent MD

Conflicts of interest: none

This work is licensed under a Creative Commons Attribution-ShareAlike 4.0 International License.

\section{REFERENCES}

1. Odell J A. The history of surgery for pulmonary tuberculosis. Thorac Surg Clin 2012;22:257-269.

2. Alexander J. The surgery of pulmonary tuberculosis. Philadelphia: Lea and Febiger, 1925. p. 17.

3. Alexander J. The collapse therapy of pulmonary tuberculosis. Springfield, Il: Charles C Thomas, 1937. p. 3.

4. Botianu PVH, Dobrica AC, Butiurca A, et al. Complex space-filling procedures for intrathoracic infections-personal experience with 76 consecutive cases. Eur J Cardiothorac Surg 2010;37(2):478-81.

5. Kuhtin O, Veith M, Alghanem M, et al. Thoracoplasty-current view on indication and technique. Thorac Cardiovasc Surg. 2018 May 17. doi: 10.1055/s-0038-1642633.

6. Giller DB, Murgustov IB, Martel' II, et al. [Repeated lung resection in patients with postoperative recurrent tuberculosis in the operated lung, in Russian]. Khirurgiia (Mosk) 2015;8:14-19.

7. Giller DB, Bizhanov AB, Khasanshin GS, et al. [Treatment of the newly diagnosed destructive lung tuberculosis with elimination of bacilli, in Russian]. Khirurgiia (Mosk) 2013;06:83-87.

8. Giller DB, Martel' II, Imagozhev YG, et al. [An experience of single lung resection and pneumonectomy after contralateral lung resection in treatment of tuberculosis, in Russian]. Khirurgiia (Mosk) 2015;09:35-42.

9. Giller DB, Sha khaev AIa, Vasil'eva IA, et al. [Efficiency of partial pneumonectomies in patients with multidrug-resistant tuberculosis, in Russian]. Probl Tuberk Bolezn Legk 2008; 05:6-10. 